\title{
Políticas públicas: imperativos e promessas de inclusão social
}

Dagmar Estermann Meyer* Maria Cláudia Dal'Igna**

Carin Klein $* * *$

Catharina da Cunha Silveira****

\section{Resumo}

Este artigo se propõe a analisar parte dos resultados de uma pesquisa que examina políticas públicas de inclusão social, focalizando seu processo de implementação, os serviços ofertados pelas secretarias municipais de educação, saúde e desenvolvimento social de um município do Rio Grande do Sul e os sujeitos que executam as ações programáticas decorrentes dessas políticas. Apoiando-se nos campos dos Estudos de Gênero, dos Estudos Culturais e da Sociologia da Saúde, naquelas vertentes que se aproximam do pós-estruturalismo de Michel Foucault, problematiza imperativos e promessas de inclusão social que contribuem para instituir processos de responsabilização dos sujeitos tanto pelo sucesso ou fracasso das ações previstas nessas políticas de inclusão social, quanto pela busca de soluções para os problemas que vivenciam no cotidiano dos serviços. Argumenta-se, ainda, que essa discursividade institui modos de organização do trabalho, bem como modos de fazer profissionais.

Palavras-chave: Políticas públicas. Inclusão social. Serviços públicos. Pósestruturalismo.

\section{A questão da inclusão social}

Dentre os argumentos mais aceitos para explicar o crescimento do Brasil, estão as chamadas políticas de inclusão social adotadas no país, nas últimas

\footnotetext{
* Doutora em Educação. Professora do Programa de Pós-Graduação em Educação da Universidade Federal do Rio Grande do Sul (UFRGS). Pesquisadora com bolsa PQ do CNPq. E-mail: dagmaremeyer@gmail.com

** Doutora em Educação. Professora do Curso de Pedagogia e do Programa de Pós-Graduação em Educação da Universidade do Vale do Rio dos Sinos (Unisinos). E-mail: mcdaligna@hotmail.com

*** Doutora em Educação. Membro do Grupo Técnico Municipal da Política Primeira Infância Melhor do município de Canoas/RS. Professora do Curso de Pedagogia da Universidade do Vale do Rio dos Sinos (Unisinos). E-mail: carink@terra.com.br

**** Mestranda do Programa de Pós-Graduação em Educação da UFRGS. Bolsista CNPq. E-mail: catharinasilveira@gmail.com
} 
décadas, como meio eficaz de redução da pobreza e da desigualdade social ${ }^{1}$. As propostas de inclusão social vêm atuando - principalmente, por meio de distribuição de renda - em articulação com as áreas de saúde, assistência social e educação; instituem, dentre outras coisas, a obrigatoriedade no cumprimento de determinadas condicionalidades por parte de seus/suas usuários/as, visando à ampliação das ações em saúde, ao acesso a direitos sociais e à profissionalização, e à diminuição da evasão e da repetência escolar. Notícias ressaltando essas ações e que dão visibilidade a algumas mudanças sociais, econômicas e políticas ocorridas nas últimas décadas podem ser lidas, cotidianamente, em jornais de grande circulação no país, bem como em reportagens publicadas no Portal Brasil ${ }^{2}$.

Ao mesmo tempo, pesquisas que examinam políticas e programas sociais questionam a ideia de evolução linear da promoção da inclusão social ${ }^{3}$. Esses estudos indicam que tais políticas, utilizando o argumento da inclusão de todos/ as, fortalecem uma cultura empreendedora ${ }^{4}$ no mundo contemporâneo, que busca formar sujeitos para serem capazes de garantirem para si as condições de permanecerem incluídos e participarem do jogo social ${ }^{5}$ - criando condições para que o Estado seja paulatinamente desobrigado disso.

1 Estudos recentes do Instituto de Pesquisa Econômica Aplicada (Ipea) apontam que os investimentos do Governo Federal em programas sociais de transferência de renda, como o Bolsa Família e o Brasil Carinhoso, têm alta eficiência para a redução da pobreza e da desigualdade social no país (BRASIL, 2012).

2 O portal funciona desde 2007, ano em que a Secretaria de Comunicação Social da Presidência da República (Secom) lançou o edital para a sua criação. A partir daí, o Grupo TV1 é responsável pelo desenvolvimento técnico e pela produção de conteúdo. Para mais detalhes, ver: <http://www.brasil.gov.br>.

3 Ver, por exemplo, as pesquisas de Carin Klein (2010), Dagmar Meyer (2005, 2008), José Damico (2011), Leticia Lasta (2009), Priscila Turchiello (2009) e Tatiana Rech (2010), assim como a reportagem sobre pesquisa encomendada ao Centro Brasileiro de Análise e Planejamento (Cebrap) pela organização europeia Christian Aid (financiadora de movimentos sociais no Brasil). A pesquisa mostra que, embora a pobreza tenha diminuído, a desigualdade entre ricos e pobres se mantém elevada, e as possibilidades de mobilidade social continuam sendo pequenas (ARRUDA, 2013).

4 Sylvio Gadelha (2009), apoiando-se nas reflexões de Michel Foucault sobre governamentalidade neoliberal, explica que a cultura do empreendedorismo migrou do domínio econômico-empresarial para outras esferas, como a da educação. Tal cultura modifica radicalmente as maneiras de pensar, agir e sentir dos indivíduos que são estimulados a avaliarem permanentemente suas ações. Como explica Gadelha (2009, p. 157): "[...] a disseminação dessa cultura, sempre em estreita conexão com a educação, com as escolas, com projetos sociais e assistenciais, esportivos e de formação técnico-profissional, vem sendo feita de tal modo a ampliar-se progressivamente, como estando associada a virtualmente tudo o que seria decisivo e bom não só para o sucesso dos indivíduos, em particular, mas também para o progresso, o desenvolvimento sustentável e o bem-estar de toda a sociedade. Não seria exagerado dizer, nesses termos, que o culto ao empreendedorismo vem sendo apresentado como a panaceia para os males do País e do mundo".

5 Utilizamos essa expressão inspiradas pelos escritos de Michel Foucault. Segundo Albuquerque Júnior (2004, p. 82), "a palavra jogo não aparece [nas obras do autor] apenas como metáfora, mas como forma de conceber o funcionamento da sociedade, de figurar como se passa a história, um modo de ver o mundo, de pensá-lo e relacionar as empirias e os conceitos. Para Foucault, a história é resultado de jogos múltiplos, de inúmeros afrontamentos entre forças e saberes, é fruto da emergência de uma dispersão de acontecimentos que são consequência de embates, que emergem em meio a forças litigantes". 
$\mathrm{Na}$ direção de situar nossa discussão, importa-nos explicar que este artigo desdobra-se de um conjunto de análises que realizamos na pesquisa intitulada Vulnerabilidade, programas de inclusão social e práticas educativas: uma abordagem na perspectiva dos estudos de gênero e culturais. Nela, buscamos discutir e problematizar resultados de um conjunto de investigações realizadas por nossa equipe de pesquisa ${ }^{6}$ - com gestores(as) e técnicos(as) implicados(as) com a implementação de políticas de inclusão social para responder às seguintes questões: que respostas e quais aprendizagens estudantes, pesquisadores(as), gestores(as) e técnicos(as) podem produzir/ fazer em processos educativos participativos que colocam as pesquisas que realizamos, nas universidades, em relação/confronto com o cotidiano das práticas desenvolvidas em programas de inclusão social, em nível de municípios da Grande Porto Alegre/RS? Quem aprende o que, com quem, sobre o que, com que implicações práticas, nesta relação?

O trabalho de campo articulou ações de extensão e de ensino de pós-graduação, e foi desenvolvido no âmbito de uma parceria entre duas instituições e vários grupos e interesses: uma universidade pública interessada em projetos que potencializam políticas públicas de caráter social; um programa de pósgraduação comprometido com formação de professores(as); uma prefeitura de um município da Grande Porto Alegre/RS e três de suas secretarias (educação; saúde; cidadania e desenvolvimento social); um grupo de estudantes-pesquisadores(as) e sua orientadora de pós-graduação stricto sensu; e gestores(as) e técnicos(as) com diferentes formações e atuantes em vários espaços ${ }^{7}$, envolvidos com a implementação e a avaliação de ações programáticas direcionadas direta ou indiretamente para a inclusão social.

6 Pesquisa financiada com recursos do Programa de Bolsas de Produtividade em Pesquisa do CNPq, vigente no período de março de 2008 a fevereiro de 2014 . A equipe de pesquisa foi integrada pelas autoras e por Jeane Félix, José Damico, Letícia Fernandes, Luiz Fernando Alvarenga e Sandra Andrade. Na condição de "pesquisa guarda-chuva", ancorou um conjunto de dissertações e teses que problematizam políticas e programas direcionados para a inclusão social, também desenvolvidas pelo grupo, na região denominada Grande Porto Alegre/RS (ALVARENGA, 2006; ANDRADE, 2008; DAL'IGNA, 2011; DAMICO, 2011; KLEIN, 2003, 2010; FERNANDES, 2008, além da já referida pesquisa de MEYER, 2008), cujos resultados tanto alimentaram a pesquisa intervenção em foco, quanto foram por ela nutridos e tensionados.

7 Os/as participantes da pesquisa tem formação nas seguintes áreas: Magistério, Pedagogia, Psicologia, Nutrição, Assistência Social, Enfermagem, Fonoaudiologia e Odontologia. No período de realização da pesquisa, atuavam nas Escolas Municipais, nas Unidades Básicas de Saúde, nos Centros de Referência de Assistência Social e nas Secretarias e Coordenadorias Municipais de Educação, Desenvolvimento Social e Saúde. Exerciam suas funções como professores/as da Educação Básica, como coordenadores/as dos projetos de inclusão escolar, como integrantes das equipes da Estratégia Saúde da Família do Sistema Único de Saúde, como coordenadores/as de Unidades dos Programas Especiais de Saúde e como psicológos/as nos atendimentos clínicos de acompanhamento familiar em grupos de convivência e/ou serviço socioeducativo. 
No conjunto desses encontros produzimos o corpus da pesquisa, o qual foi composto por um conjunto de textos com diferentes características: registros escritos acerca dos processos de negociação e planejamento do curso; diários de campo produzidos durante sua implementação e, ainda, grupos focais realizados com gestores(as) e técnicas(os) das secretarias de educação, saúde e desenvolvimento social ${ }^{8}$.

Para desenvolver as análises, buscamos apoio nos campos dos Estudos de Gênero, dos Estudos Culturais e da Sociologia da Saúde, naquelas vertentes que se aproximam do pós-estruturalismo de Michel Foucault ${ }^{9}$. Acrescentam-se a esse quadro teórico-metodológico as discussões acerca da vulnerabilidade, da educação permanente e da pesquisa-ação. Tal articulação constituiu-se, no contexto de nossa pesquisa, em um desafio, tendo em vista a proximidade dessas últimas abordagens com as teorizações emancipatórias, e implicou um investimento na direção de discutir teoricamente as potencialidades e os limites teórico-políticos dessa articulação ${ }^{10}$.

8 Programa de encontros semanais ao longo do segundo semestre de 2009, de 48 horas-aula, que contemplou três eixos temáticos: 1) os conceitos de risco, vulnerabilidade e inclusão social e suas implicações práticas; 2) o conceito de família e seu posicionamento como alvo e como agente de inclusão social (de crianças, jovens, mulheres e idosos): possibilidades e limites; 3 ) saúde, escolarização e acesso a serviços sociais básicos como estratégias de inclusão social: possibilidades e limites. Participaram 22 técnicos(as) e gestores(as) atuantes nas secretarias envolvidas, seis estudantes de pós-graduação ou recém-doutores, a coordenadora da pesquisa e uma bolsista de iniciação científica. Tal programa foi aprovado pela PROREXT/ UFRGS como projeto de extensão e, dessa forma, os(as) informantes puderam ser certificados por sua participação. Os(as) participantes do município foram autorizados(as) a associar-se à pesquisa em seu horário de trabalho e sua adesão foi oficializada com a assinatura de um termo de consentimento informado.

9 Pressupostos básicos desta pesquisa, aqui utilizados, são: um primeiro, que permite conceber cultura como um campo de luta e contestação em que se produzem tanto os sentidos quanto os sujeitos que constituem os diferentes grupos sociais em sua singularidade (GILES; MIDLETTON, 1999); um segundo, que defende a centralidade da linguagem (em sentido amplo) nos processos de significação do mundo em que vivemos, para tratá-la como lócus de produção das relações que a cultura estabelece entre corpo, sujeito, conhecimento e poder (HALL, 1997); um terceiro, que entende educação como conjunto de processos pelos quais indivíduos são transformados ou se transformam em sujeitos de uma cultura. Nessa direção, tornar-se sujeito de uma cultura envolve um complexo de forças e de processos de aprendizagem que, nas sociedades contemporâneas, estão fortemente imbricados em políticas e programas públicos, em especial aqueles que envolvem os campos da saúde e da educação (SHORE; WRIGHT, 1997); um quarto, que deriva da confluência desses pressupostos, e sugere problematizar as políticas (em sentido lato) como linguagem, como artefato cultural e como tecnologia de poder, por entender que elas têm se tornado um instrumento central de organização das sociedades contemporâneas. Como instrumentos de organização da sociedade, elas tanto incidem sobre os modos pelos quais os indivíduos constroem a si mesmos como sujeitos, e com isso, modificam mais ou menos suas condições de vida, quanto instituem formas de categorização desses sujeitos (cidadãos, adultos e crianças saudáveis, gestores e técnicos da inclusão social, famílias em situação de risco ou vulneráveis etc.), e por isso incidem de tal forma sobre a vida de determinados indivíduos e populações que se torna virtualmente impossível ignorá-las ou escapar delas (SHORE; WRIGHT, 1997).

10 Por exemplo, a ênfase problematizadora das abordagens pós-estruturalistas quando colocada em relação com as aspirações emancipatórias e transformadoras das intervenções propostas, e os sentidos atribuídos a conceitos como sujeito, emancipação e autonomia, nessas duas abordagens (educação permanente e pesquisa-ação), para citar algumas das dimensões, neste momento. 
Do conjunto de análises que realizamos na pesquisa citada, pretendemos examinar, neste artigo, alguns imperativos e promessas das políticas públicas de inclusão social, focalizando seu processo de implementação, os serviços ofertados pelas secretarias de educação, saúde e desenvolvimento social e as profissionais técnicas ${ }^{11}$ implicadas com a implementação de ações programáticas direcionadas direta ou indiretamente para a inclusão social.

Argumentamos que, ao fazê-lo, torna-se possível descrever e analisar processos de responsabilização das profissionais pelo sucesso ou fracasso das ações previstas nessas políticas sociais e, também, pela busca de soluções para os problemas que vivenciam no cotidiano dos serviços, para pensar no que estamos nomeando como imperativos e promessas que as políticas de inclusão social produzem e em como as profissionais que nelas atuam são posicionadas, ao mesmo tempo, tanto como responsáveis por problemas sociais complexos quanto por sua resolução.

Essa nos parece uma questão relevante a ser explorada, tendo em vista, como já argumentamos na introdução desse artigo, a proliferação das chamadas políticas de inclusão social adotadas no país, nas últimas décadas, como meio eficaz de redução da pobreza e da desigualdade social. Tal exercício analítico permite examinar de que modos os imperativos e as promessas de inclusão social incidem sobre os sujeitos gestores e técnicos e sobre seus contextos profissionais, na medida em que essa discursividade institui, também, modos de organização do trabalho nas instituições e serviços implicados com a inclusão social, bem como modos de fazer profissionais, que ela também produz nos mesmos processos.

Em consonância com essa argumentação, recortamos para este artigo um movimento analítico que atenta para a concepção e as condições de trabalho (materiais e simbólicas), aos contextos institucionais em que políticas e programas se materializam como ações programáticas, e aos modos como profissionais atuantes nas secretarias municipais, e/ou em espaços que se desdobram destas, envolvem-se com esses contextos para sustentarmos o presente artigo. Passamos agora a explorar a primeira questão.

11 No contexto deste artigo, daqui em diante, utilizaremos as expressões as profissionais e as técnicas para referir-nos, respectivamente, às técnicas das secretarias de Educação, Saúde e Desenvolvimento Social, porque as participantes da pesquisa, aqui citadas, são todas mulheres. A distinção - os(as) profissionais, os(as) técnicos(as) - será mantida quando for importante para a análise desenvolvida. 


\section{Inclusão social nas políticas contemporâneas}

Durante a introdução deste artigo, argumentamos sobre a importância de examinarmos a produção de uma discursividade sobre o tema da inclusão social. No espaço limitado deste texto, não poderemos aprofundar a análise do tema; assim, apresentaremos, brevemente, alguns sentidos utilizados na bibliografia.

Aécio Amaral Júnior e Joanildo Burity (2006) afirmam que o assunto tem sido mais enfatizado na agenda pública brasileira desde a segunda metade dos anos 1990. Os autores analisam a forte conexão entre os temas da inclusão/exclusão social e as reformas do Estado, que passaram a incentivar a participação da sociedade civil nas tomadas de decisão e nas políticas públicas.

Romeu Sassaki (2003) explica que estamos vivendo um tempo de muitas mudanças, e que a promoção da inclusão social está envolvida com os valores e os paradigmas vigentes numa determinada época histórica. Apresentamos a seguir, de forma resumida, dois paradigmas analisados pelo autor:

1) O paradigma da integração social pode ser traduzido como uma estratégia de adaptação das pessoas ditas excluídas da sociedade. Nesse sentido, as políticas deveriam criar formas de adaptação para que as pessoas pudessem fazer parte da sociedade.

2) O paradigma da inclusão social não se refere à adaptação, mas à mudança. É necessário trabalhar para mudar a sociedade, criando políticas e leis, tornando-a um lugar adaptado às pessoas e a suas necessidades.

Namesma direção, Maria João Militãoe Carla Pinto(2008), ao examinarema política portuguesa de inclusão, explicam que o conceito é polissêmico e multidirecional. Uma visão dominante definiria inclusão social como "uma situação na qual todo o membro de uma sociedade consegue participar efectivamente na vida social [...]" (MILITÃO; PINTO, 2008, p. 9). Mais recentemente, essa compreensão avançou na União Europeia para a ideia de inclusão ativa, através da qual

[...] o Estado deve proporcionar aos cidadãos percursos personalizados que levem à inserção laboral, ou então o reconhecimento da incapacidade para o trabalho, assegurando nestes casos meios para uma vida condigna, bem como outras oportunidades de utilidade à sociedade [...]. Neste modelo a chave para a inclusão é a integração no mercado de trabalho. (MILITÃO; PINTO, 2008, p. 9-10). 
Os autores e as autoras aqui citados(as) fornecem elementos importantes para que possamos compreender como alguns sentidos sobre inclusão social tornamse aceitáveis, desejáveis e naturais. No caso da inclusão social, pode-se afirmar que ela é, frequentemente, definida como um movimento de enfrentamento das diversas formas de exclusão para promoção da igualdade. Nas palavras de Sassaki (2003, p. 2), "a inclusão social consiste em tornarmos a sociedade toda um lugar viável para a convivência entre pessoas de todos os tipos e condições na realização de seus direitos, necessidades e potencialidades".

É num cenário de disputas em torno dos sentidos da inclusão que muitas políticas sociais se movimentam, ganham e produzem significados. A fim de problematizar alguns desses sentidos naturalizados, examinaremos a seguir algumas noções de inclusão social presentes nas ações desenvolvidas pelas profissionais técnicas pesquisadas, buscando compreender, não apenas a constituição do significado para determinados sujeitos, mas os efeitos de determinados significados em suas ações.

É importante ressaltar, entretanto, que ao falarmos sobre a produção de determinados efeitos, tornou-se relevante, para nós, examinar processos de in/exclusão produzidos no âmbito de ações programáticas diversas ${ }^{12}$, desenvolvidas com base em diretrizes do governo federal e, portanto, derivadas dessas políticas de inclusão social, focalizando seu processo de implementação e as profissionais técnicas que as executam.

Vejamos, então, o que dizem algumas técnicas sobre os efeitos do Programa Bolsa-Família ${ }^{13}$ na vida das famílias beneficiárias:

12 No caso do grupo de participantes da pesquisa, principalmente: Bolsa Família, Mais Educação, Educação de Jovens e Adultos, Saúde da Família, Primeira Infância Melhor, Programa de Atenção Integral à Família, Primeiro Emprego, dentre outros. Não nos detivemos, entretanto, na análise de especificidades de tais políticas/programas, mas naqueles desafios/entraves/soluções que compõem os cotidianos de trabalho que envolvem sua implementação.

13 O Programa Bolsa Família (PBF) dirige suas ações às famílias em situação de pobreza e extrema pobreza em todo o país e integra o plano do Brasil sem Miséria. Possui como foco de atuação os 16 milhões de brasileiros com renda familiar inferior a 70 reais per capita e tem como eixos: a transferência de renda a fim de promover o alívio imediato da pobreza; o cumprimento das condicionalidades para ampliar o acesso a direitos sociais básicos nas áreas de educação, saúde e assistência social; e a participação nas ações e programas complementares que objetivam o desenvolvimento das famílias, de modo que os beneficiários consigam superar a situação de vulnerabilidade. É interessante demarcar que, ao mesmo tempo em que se responsabiliza a família pelo cumprimento dessas condicionalidades, o cartão continua sendo feito, de preferência, em nome da mulher, que deverá ocupar o lugar de responsável legal pela família. É o cumprimento destes compromissos que garante a permanência no programa: matricular crianças e adolescentes de seis a 17 anos na escola, garantir o mínimo de $85 \%$ de frequência mensal às aulas, acompanhar o aprendizado e comparecer às reuniões escolares. Já os estudantes entre 16 e 17 anos devem ter frequência de, no mínimo, 75\%. Os responsáveis pelas crianças menores de sete anos precisam manter atualizado o calendário de vacinação, além de levá-las para pesar, medir e realizar exames clínicos, conforme o calendário do Ministério da Saúde. As gestantes e as mães que amamentam têm de fazer o pré-natal e comparecer às consultas na unidade de saúde, continuar o acompanhamento pós-parto de acordo com o calendário do Ministério da Saúde e participar das atividades educativas propostas pelas equipes de saúde. Para mais detalhes, ver: <http://www.mds.gov.br/bolsafamilia> . 
Uma das técnicas, que é nutricionista, apresenta o Bolsa Família e diz que essa ideia de ruptura da pobreza é uma piada. Outra afirma que elas [as famílias] não querem fazer os cursos, preferem ficar recebendo o dinheiro. A assistente social diz que o Bolsa Família, embora seja o maior programa de inclusão social até hoje, ele é um programa de acomodação social. Por fim, a professora acrescenta que para as famílias um filho representa mais $R \$ 15,00$. Porque esse tipo de família não vê como a gente vê.

Fonte: Diário de Campo, 16 de outubro de 2010.

Ao analisarmos as falas das técnicas de diferentes secretarias (Educação, Saúde e Desenvolvimento Social), ou seja, de quem representa a política em seu município e se torna responsável pela implementação das ações do Programa Bolsa Família, podemos sistematizar três argumentos. Primeiramente, é possível dizer que o programa se apoia em noções de inclusão social abertas e abrangentes. As falas indicam que a inclusão social configura-se, por exemplo, como "ruptura da pobreza". A distribuição de renda, por meio de bolsas, garantiria a condição de participação no jogo social e, consequentemente, a eliminação das condições de exclusão vividas pelas famílias beneficiárias. Se, por um lado, a bolsa produz efeitos concretos na vida dessas famílias - ampliação da renda e de consumo, acesso a cursos de capacitação; acesso à educação e à saúde, entre outros -, por outro lado, não garante que essas famílias tenham condições de se manterem incluídas, afastando permanentemente o risco da exclusão social. Como explica Lopes (2009), a distribuição de recursos garante condições mínimas de participação no jogo social, mas não oferece uma mudança radical em suas vidas. Trata-se, desta perspectiva, "de um Estado que, cada vez mais, mantém a pobreza, sem necessariamente investir em mudanças políticas, em mudanças sociais e em mudanças econômicas que possam reverter, mesmo que minimamente, a situação de pobreza e de miséria da Nação" (LOPES, 2009, p. 162).

Dessa posição, podemos passar ao segundo argumento que dela se desdobra. Pode-se dizer que as falas das técnicas fazem sentido em um contexto de confrontos e de negociações culturais que envolvem relações de poder $^{14}$ sobre o que se estabelece como inclusão social em um contexto de extrema pobreza. Pode-se argumentar que, no âmbito das ações que visam à inclusão social das

14 Nesse contexto, é importante referir que o pós-estruturalismo, especialmente o conceito de poder desenvolvido por Foucault, tem contribuído para a problematização desses confrontos e negociações. Foucault (1995) desloca o poder de seu suposto centro e subverte a noção de poder binário (oprimido/opressor). O poder, para o filósofo, não é repressivo: ele incita, provoca, produz. Ele não é algo que alguém possui, mas que exerce. 0 poder é produtivo na medida em que seu exerć́cio tem efeitos sobre os sujeitos - efeitos que não são apenas coercitivos, e exercício que se constitui num jogo permanente de disputa. O autor argumenta ainda que o exercício do poder, no sentido do seu funcionamento, implica resistência numa mesma rede de forças. É uma ação sobre outra ação, que se exerce sobre sujeitos livres e que produz efeitos, respostas e reações. 
famílias, elas vivenciam condições de in/exclusão, pois, enquanto a política promove a ampliação da renda e do consumo, o acesso a cursos de capacitação e permanência dos(as) filhos(as) na escola e participação em determinadas ações de saúde, institui, ao mesmo tempo, operações de normalização que identificam as irregularidades dessas famílias, posicionando-as como negligentes, acomodadas e/ ou inadequadas para a promoção do desenvolvimento saudável dos(as) filhos(as). Meyer, Klein e Fernandes (2012) apontam, com base em suas pesquisas, que os programas governamentais de inclusão social mobilizam as famílias garantindo condições mínimas para que elas permaneçam incluídas na vida social, e que faz-se um investimento para que tais famílias sejam acompanhadas e estimuladas a tornarem-se agentes de inclusão social. Os programas produzem, assim, uma

[...] ampla veiculação de um discurso que visa atingir todos os indivíduos e ensiná-los a dirigir as suas próprias vidas (e as de suas famílias) [...] através da produção de mudanças de comportamento, de adaptação a regras e normas, de controle social e de formação para utilizar adequadamente o que ali se define como suas aptidões e competências. (MEYER; KLEIN; FERNANDES, 2012, p. 442).

Por fim, é possível formular, ainda, um terceiro argumento. Embora as políticas de inclusão social visem a orientar as famílias para dirigi-las em favor do jogo social, não se tem nenhuma garantia de que as estratégias utilizadas produzam os resultados esperados. Ao contrário disso, elas podem contribuir para reforçar comportamentos que desejam modificar. Isso pode ser observado nas falas das técnicas sobre os cursos de capacitação vinculados ao programa. Segundo elas, tais cursos (os quais podem ser compreendidos como estratégias educacionais) não interessariam ao públicoalvo (famílias beneficiárias), pois, uma vez capacitadas, perderiam a remuneração oferecida pelo programa. Além disso, em sua perspectiva, também a distribuição de renda promovida pode assumir um sentido negativo, porque acabaria reforçando a "acomodação social". Esses argumentos contribuem, pois, para o questionamento das noções de inclusão social destacadas anteriormente, pondo em xeque seus pressupostos de essencialidade, homogeneidade e universalidade.

Operando com a teorização foucaultiana, Alfredo Veiga-Neto e Maura Lopes ${ }^{15}$ problematizam os conceitos de inclusão e exclusão no contexto das

15 Para aprofundar a análise sobre essa problematização, vide Lopes (2009), Veiga-Neto (2008, 2011) e Veiga-Neto e Lopes (2011). 
políticas de inclusão escolar. Nesse contexto, Lopes (2009) argumenta que a inclusão é uma invenção moderna profundamente implicada com um projeto de sociedade preocupada cada vez mais com aqueles que não estão incluídos. É preciso incluir para conhecer, controlar, vigiar e governar. Pode-se, desde esse ponto de vista, questionar certa banalização de um conceito unívoco de inclusão como resposta à exclusão, para compreendê-la como prática de regulação e controle; como conjunto de práticas que agem sobre o indivíduo e a população; como um imperativo.

Tomar a inclusão como um imperativo implica, como decorrência, o questionamento de três entendimentos correntes em nossa cultura. Em primeiro lugar, a inclusão social tem sido entendida como algo natural. Em segundo lugar, ela tem sido compreendida como algo bom em si mesmo. Por fim, ela tem sido apresentada como necessária. Assim assumida, a inclusão social estaria desde sempre aí, esperando para ser efetivada. É a isso que chamamos de imperativo. "É preciso promover a inclusão, pois é natural que assim seja" (VEIGA-NETO, 2008, p. 20).

Haveria razões para suspeitarmos disso? Acreditamos que sim. Por isso, com este artigo, propusemos um breve exercício analítico sobre o tema da inclusão social. Queremos, com ele, destacar a importância de suspeitarmos do que é pensado e dito sobre o tema, examinando alguns aspectos do que, nele, parece natural. Isso significa analisar os processos que vão constituindo e organizando algumas ações como desejáveis (ou não), por parte de quem atua nas políticas sociais - seus/suas profissionais - para entrar no jogo da inclusão.

Mas é preciso fazer uma ressalva. Tomando como base o campo dos estudos foucaultianos, a crítica que propomos desconfia das certezas, mas não pretende (des)qualificá-las ou destruí-las. Dizendo com outras palavras, não pretendemos afirmar que a inclusão social não deva existir, ou que não devamos almejá-la, persegui-la, lutar por ela. Para nós, problematizar o conceito de inclusão implica, também, a problematização do conceito de exclusão. Tomando como base os estudos de Michel Foucault (2008a, 2008b) e Zygmunt Bauman $(2005,2008)$, é possível afirmar que a exclusão não existe em si mesma, não está desde sempre aí. Ela é uma invenção deste mundo. Ela é condição necessária para o gerenciamento de todos numa sociedade inclusiva que objetiva a inclusão de todos(as), sua distribuição, 
classificação e hierarquização. Trata-se, desse ponto de vista, de um jogo que coloca em ação operações de comparação, diferenciação, hierarquização, homogeneização e exclusão. São esses processos que possibilitam medir os desvios e colocar todos sob uma norma ${ }^{16}$. Entretanto, as medidas utilizadas para estabelecer graus de normalidade são parciais e provisórias.

O problema, então, muda e passa a ser a (in)definição do termo inclusão, uma vez que, como sinaliza Robert Castel (2008), para analisar situações sociais complexas é necessário tassumir que categorias de incluído e excluído não são suficientes. Ao examinar a situação de jovens de periferia, o autor argumenta que estes não podem ser simplesmente classificados como excluídos. Sua condição será alterada conforme o critério utilizado para definição: marcadores de ordem econômica, social, política, racial, psicológica, pedagógica, entre outras. Sobre essa questão, Lopes (2009) explica que, na contemporaneidade, a proliferação das políticas de assistência, ainda que não promova mudanças permanentes, torna a exclusão uma possibilidade cada vez mais remota.

Assim, esse movimento de questionamento dos conceitos permite colocar em questão a fórmula inclusão versus exclusão, para analisar a relação entre os termos. Trata-se menos de uma oposição de termos (e, portanto, também de situações/condições sociais) que se antagonizam do que de uma relação mútua e permanente. Mais do que tratar de um ou outro, melhor seria falar em in/exclusão (LOPES; DAL'IGNA, 2007; LOPES et al., 2010). Isso exige que consideremos tanto a relação entre inclusão e exclusão, quanto a impossibilidade de definir, isoladamente, cada um desses termos.

Dar visibilidade a esse processo de produção discursiva dos conceitos nos possibilita abordar o tema das políticas de inclusão de outro modo. Em vez de partirmos do pressuposto de que as políticas promovem inclusão, pode-se perguntar, por exemplo: quais são as implicações das políticas de inclusão social na construção de novas/outras fronteiras de exclusão/inclusão? Ao promover a inclusão, as políticas de inclusão estariam, ao mesmo tempo, implicadas com a produção de novas/outras diferenças e desigualdades? Como os(as) profissionais que atuam no contexto da inclusão social efetivam e dão sentido às suas ações no contexto de tais políticas?

16 No contexto deste artigo, a norma é compreendida como uma medida e um princípio de comparabilidade. A norma opera no sentido de incluir a todos; portanto, normais e anormais estão na norma. Para mais detalhes, ver: Canguilhem (2002), Ewald (2000) e Foucault (2000). 
Antes de discutirmos essas questões, importa esclarecer que estamos compreendendo as políticas de inclusão social como prática política de governamentalidade, como manifestações da governamentalização do Estado moderno (VEIGA-NETO; LOPES, 2011). Como sinaliza Meyer (2008) no projeto de pesquisa do qual deriva esta análise, as políticas de inclusão social devem ser analisadas tomando como foco os processos de gestão da vida e as redes de poder-saber aí delineadas, as quais atravessam e constituem conhecimentos que sustentam e conformam tais políticas. Naquilo que nos interessa discutir, os investimentos educativo-assistenciais promovidos pelas políticas de inclusão

[...] contribuem para re-significar o que se entende e se vive como família e como relação mãe-fillho, e re-inscrevem esses sujeitos em um poderoso regime de vigilância e regulação, forjando discursos sobre família, sobre paternidade e maternidade, e sobre infância e juventude saudáveis. (MEYER, 2008, p. 4).

Dizendo de outro modo, junto desses autores e autoras, afirmamos que as políticas de inclusão social estão implicadas tanto com a condução das condutas humanas quanto com os mecanismos e as imposições de sentidos e de formas de vida produzidas e legitimados em determinados contextos histórico-culturais. Trata-se de um jogo entre corpo individual e corpo coletivo, que posiciona o indivíduo como alvo de práticas educativas e assistenciais, e que visa produzir sujeitos capazes de conduzir sua própria vida.

Assumindo tais posições, passamos agora à discussão sobre o processo de responsabilização das profissionais que implementam ações no âmbito das políticas de inclusão social.

\section{3 "Nós representamos a política": as agentes da inclusão social}

A pesquisa desenvolvida com as técnicas oportunizou que muitas coisas pudessem ser pensadas. Permitiu, sobretudo, dar visibilidade às ações derivadas de políticas de inclusão social - que são desenvolvidas por elas nos espaços em que atuam com o objetivo de incluir - conhecer e governar - grupos sociais ditos excluídos (famílias em situação de vulnerabilidade social, por exemplo). 
Durante a realização de um grupo focal, uma técnica deu alguns indicativos de como as políticas sociais produzem efeitos nas ações desenvolvidas por elas.

Técnica da Secretaria Municipal de Saúde (TSMS): A política pública vem num formato e a pessoa se ajusta a ela, quando deveria ser ao contrário, a política se ajustar àquela pessoa, àquela demanda [...] os formatos são bem prontos. Na verdade, eu, técnica, atuando hoje numa política pública de saúde da família, a política está pronta, eu não ajudei a política a ser construída, tem coisas que são quase obrigatórias fazer, por exemplo, tem que ter grupos de hipertensos nas equipes, ok, mas se o hipertenso não quer grupo? Se ele quer outra coisa? Não existem essas brechas, vem o protocolo pronto, o técnico poderia, de repente, interagir mais com o usuário, trabalhar as questões de uma forma diferenciada do protocolo, mas tem coisas que não dá pra fugir, ele vai ter que ter um cadastro, ele tem que ter registrado aqueles grupos, sabe? E o recurso fica vinculado ao cumprimento dessa rotina, vai daí do envolvimento do caráter pessoal [dos(as) técnicos(as)], o caráter pessoal da atividade, como é que vai fazer a realização do grupo? Tu vai aproveitar o potencial das pessoas ou tu vai trazer tudo pronto?

Fonte: Grupo focal, 9 de abril de 2010 - grifos nossos.

Esse excerto de fala dá pistas de como as políticas sociais operam com base em determinadas normas que prescrevem, aos sujeitos com elas envolvidos, a incorporação de determinados comportamentos e ações específicas.

Nessa direção, ressaltamos também o exemplo de duas ações desenvolvidas pelas profissionais técnicas pesquisadas. Para participar do Programa Bolsa Família (PBF), por exemplo, a família beneficiária deve cadastrar-se no programa, acompanhar a frequência e o desenvolvimento do(a) filho(a) na escola, manter atualizado o calendário de vacinação das crianças com menos de sete anos, além de levá-las para pesar, medir e realizar exames clínicos conforme o calendário do Ministério da Saúde (BRASIL, 2012). Por meio das Unidades Básicas de Saúde (UBS), a gestante também é vinculada à Rede Cegonha ${ }^{17}$, para que tenha acesso aos cuidados pré-natais, realize os exames de rotina e receba um apoio financeiro para os momentos que envolvem o parto. Além disso, a equipe de atenção básica deve acompanhar essa gestante, de modo que possa ser prestado cuidado integral à gestante $\mathrm{e}$ sua família (BRASIL, 2011).

17 A Rede Cegonha foi instituída no âmbito do Sistema Único de Saúde (SUS), através da portaria n 1.459 , de 24 de junho de 2011. Tem como objetivo principal congregar um conjunto de ações a fim de garantir $\mathrm{o}$ atendimento de qualidade, seguro e humanizado para todas as mulheres. As ações buscam oferecer assistência desde o planejamento familiar, acompanhar os momentos da confirmação da gravidez, o pré-natal, o parto, os 28 dias pós-parto (puerpério), cobrindo até os dois primeiros anos de vida da criança. Sua estrutura está organizada em quatro componentes: pré-natal, parto e nascimento, puerpério e atenção integral à saúde da criança e sistema logístico que se refere ao transporte sanitário e regulação. Para mais informações, ver: <http://bvsms.saude.gov.br/bvs/folder/rede_cegonha.pdf >. 
Delineia-se, aí, a criação de uma ampla rede de cuidados circunscritos por essas políticas e programas, na qual e por meio da qual, ao mesmo tempo em que se busca assegurar às famílias em situação de vulnerabilidade social os direitos e o acesso à saúde, estão se produzindo determinados efeitos que atingem tanto os(as) profissionais quanto os(as) beneficiários(as). Dizendo de outro modo, as políticas e os programas de inclusão social produzem imperativos que preconizam formas inerentes de viver a gestação, a infância e a maternidade, bem como formas específicas de ser e agir como profissional técnica(o) no âmbito dessas ações: educando, orientando, acompanhando, avaliando de determinados modos.

Nessa direção, Meyer (2008, p. 6) aponta que "as políticas funcionam como uma estratégia pedagógica e de organização social que pretende promover a inclusão social através da normatização e administração de certas dimensões da vida cotidiana dos sujeitos aos quais se direcionam". Do mesmo modo, Patrice Schuch e Claudia Fonseca (2009) destacam a importância de análises centradas nas dinâmicas e nas experiências dos indivíduos envolvidos com a formulação das leis, campanhas, políticas e no funcionamento das instituições, tomando-as como elementos constitutivos de normas e de arranjos que viabilizam a vida cotidiana e diferentes projetos de sociedade.

O exame de outros excertos de conversas desenvolvidas durante a realização do grupo focal nos permite elencar mais alguns desses efeitos:

Pesquisadora: Vocês já pensaram como muitas vezes, como a gente viu no filme18, como a mãe se culpabilizou, como nós, técnicos, também nos responsabilizamos?

Técnicas juntas: Aham!

Técnica da Secretaria Municipal da Saúde (TSMS) 1: Mas por que nós nos responsabilizamos? Porque a gente tá trabalhando pela política pública, mas que mecanismos nós na ponta podemos utilizar para mudar essa realidade que tá inscrita num formato que não tá servindo?

TSMS2: Nós representamos perante aquela pessoa a política pública.

TSMS1: Exatamente...

\section{$[\ldots]$}

Técnica da Secretaria Municipal do Desenvolvimento Social (TSMDS) 119: [...] É isso que tu disseste, essa culpa, nós falhamos, mas daí numa reunião com a diretora me questionaram: "mas por que tu acha que nós falhamos?" Claro que nós falhamos, porque no momento que tu acolhe tu tá dizendo que tu vai proteger e nós não conseguimos proteger essa pessoa, devolvemos, não é? Ela chega e diz que quer ir embora e a gente sabe por que que ela quer

18 Documentário sobre o programa Primeira Infância Melhor (PIM), produzido pela rede britânica BBC de televisão. Disponível em: <http://www.pim.saude.rs.gov.br/a_PIM/php/index.php>.

19 Fala referente a uma situação de violência doméstica encaminhada pela secretaria. 
ir embora, ela tá num albergue cheio de homens e ela diz assim: "quando ele souber que eu tô nessa situação daí que ele acaba comigo".

\section{$[\ldots$.}

Técnica da Secretaria Municipal da Educação (TSME) 1: Eu digo que piorou... O conselho tutelar com as nossas crianças lá na escola, o que acontece muitas vezes é eles tentam de várias formas recolher das famílias naquela situação e não tem solução. O que eles fazem? Devolvem pro lar, daí apanha mais, ficam revoltados ainda com quem prometeu que ia ajudar e na verdade...

$[\ldots]$

TSMS1: [...] Muitas vezes nós vamos lá mexer numa realidade para piorar. Tu quer mudar aquela realidade, quer mudar, quer mudar...

TSMDS1: [...] Nós não temos condições de atender a todos [...], então como é que nós noticiamos que nós vamos atender a denúncia de violência, que nós vamos resolver a denúncia [...], isso tá acontecendo, isso me incomoda muito, de tu usar de uma política pública... Partidária, fazer campanha em cima de uma questão que não é política, daí eu acho que nós temos que nos organizar melhor [...] Mas assim, se a gente técnico não se posiciona melhor [...]

TSMS1: Isso é todo dia...

TSMDS1: Todo dia...

$[\ldots]$

TSMS1: Nós tivemos um evento horrível... Na zona de crack mesmo, mandada pelo traficante. Uma situação [em] que a equipe entrou pra dentro de uma residência e o traficante deu uma ordem pra um menino. [...] Nós não temos o que fazer porque ali eles são comandados pelo traficante [...] toda aquela população ali que está à mercê das ordens daquele homem. [...] Se a Secretaria da Saúde não tem pernas para assumir isso daí, quem sabe a Secretaria de Segurança, poderia ter sido feita uma denúncia, mas as pessoas que vão ficar ali... Quem vai [virar] o suspeito de fazer isso dali, quem vai arcar com essa consequência?

TSMDS1: Aham. Quem é que sabe? É quem tá na ponta [...] Mas aí quem sabe disso? É quem tá ali na ponta, porque quando tu vai abordar, tu vê que a coisa é muito mais complexa, como vamos tirar as criaturas da rua e botar numa escola?

TSMS1: E como é que a política pública lida com isso? Age só lá no final da história, tira da rua...

TSME1: E o resto fica igual...

TSMDS1: É nesse sentido que nós temos que nos articular mais, não sei de forma, ou com que poder, eu acho que aí é o poder técnico, mas não sei até aonde a gente vai com esse poder, [...] porque depois nos cobram: "por que não estão tirando as crianças do centro da cidade?

TSME1: Porque não tem equipamento...

TSMS1: Nós temos que tirar as crianças [...].

Fonte: Grupo focal, 16 de abril de 2010 - grifos nossos. 
No exame desses excertos, podemos acompanhar o diálogo entre técnicas implicadas com a elaboração e a execução de políticas de inclusão social nesse município, com a mediação de uma das pesquisadoras. Neles, observamos essas profissionais narrando seus contextos de trabalho e dia-a-dia profissional, com base em pressupostos de inclusão e exclusão que podem ser facilmente localizados nas políticas públicas de assistência, educação e saúde. Preconizamse determinadas formas de realizar a inclusão que passam a atravessar o fazer dessas profissionais, e acabam por constituí-las como sujeitos que se pensam e se sentem responsáveis pelos indivíduos com os quais trabalham, também ensinando e conduzindo suas ações nessa direção.

Nessa discursividade, uma dada forma de responsabilização recai sobre as técnicas que se veem posicionadas diante de situações extremamente complexas, como alguém que deve "acolher", "proteger" e "mudar a realidade de uma vez para sempre", ao mesmo tempo em que se sentem despreparadas e desequipadas para atender às demandas impostas por essa complexidade. É nesse sentido que interessa, aqui, estabelecer algumas relações entre os sentidos atribuídos à responsabilização dos(as) profissionais que atuam em contextos de inclusão social, perguntando-nos: de que forma as noções de inclusão social contidas nessas políticas sociais delimitam sentidos de responsabilização, na ótica de quem implementa ações de inclusão?

Os excertos das falas indicam que essa responsabilização é significada pelos profissionais como parte, ou consequência, de seu comprometimento, profissionalismo e/ou ética profissional e social. Na mesma direção, ao não dar conta de tais promessas, seus fazeres profissionais assumem os sentidos daquilo que é entendido como desresponsabilização e desatenção ao usuário da política. Há uma culpabilização individual por processos que são mais amplos. Em pesquisas anteriores, Meyer $(2006,2008)$ defendeu o argumento da politização contemporânea da maternidade, desenvolvendo a ideia de que representações do que é ser boa mãe, articuladas em diversas e distintas instâncias sociais, constituem uma discursividade que conecta formas de viver e sentir a maternidade a problemas sociais contemporâneos, "em uma operação que permite descolar tais problemas dos contextos e problemas socais mais amplos em que eles são gerados para vincular sua solução a determinados tipos de relação mãe-filho e ao exercício de determinada forma de exercício da maternidade" (MEYER, 2006, p. 82). Com a pesquisa atual, é possível reafirmar 
que, quando se trata de populações pobres a serem interpeladas por políticas de inclusão social, mulheres mães têm sido efetivamente responsabilizadas pelos problemas sociais detectados, e como parceiras do Estado para promover sua solução. Mas torna-se possível, também, entender que essa responsabilização é muito mais ampla e complexa, ou seja: para realizar as propostas estabelecidas pelo Estado, os(as) técnicos(as) têm sido igualmente responsabilizados a fim de cumprir um conjunto de demandas que encobrem conflitos sociais, políticas e econômicas muito mais amplas, profundas e complexas ${ }^{20}$. É nesse mesmo contexto discursivo que situamos os excertos em destaque e lançamos questões a fim de desnaturalizá-lo. Como se chega a naturalizar essa responsabilização e culpabilização individual por problemas que são gerados e gestados não apenas por vontades de cada uma ou de todos(as) os(as) profissionais de um serviço?

Nessa direção, o esforço de desnaturalizar e politizar tais sentidos pode nos ajudar a evidenciar o quanto e como a lógica do trabalho, as instâncias administrativas e burocráticas dos serviços, os conhecimentos, o caráter multifacetado das ações (que responde a múltiplos interesses) que caracterizam tais políticas públicas constituem, programaticamente, processos de trabalho que posicionam essas profissionais como responsáveis por, num cotidiano de trabalho em que muitas ações e objetivos se sobrepõem e, algumas vezes, até mesmo se (des)autorizam e/ou se inviabilizam.

Com isso, não estamos argumentando que a responsabilidade individual não seja necessária e desejável e que não haja necessidade de criar/inventar soluções específicas para determinadas situações e, exatamente por isso, é necessário distinguir responsabilidade com o trabalho desse processo de responsabilização. $\mathrm{O}$ que estamos argumentando é que pode se instaurar uma paralisia política e intelectual quando os entraves cotidianos passam a ser significados como dificuldades pessoais. E, da mesma forma, quando as coisas acontecem apenas por meio de, ou como decorrência de movimentos pessoais, isso seria da ordem da responsabilização.

Ao mesmo tempo, é importante destacar que, embora seja possível identificar nas falas das técnicas sua responsabilidade com os processos de trabalho, parece haver pouco espaço efetivo para que os saberes daqueles(as) que estão na linha

20 Esse movimento de dupla responsabilização foi analisado por nós em outro artigo derivado desta pesquisa, o qual se encontra em processo de avaliação para publicação: "Vulnerabilidade, gênero e políticas sociais: a generificação da 'inclusão social'" (MEYER et al.). 
de frente dos serviços sejam ouvidos(as) e, consequentemente, debatidos e incorporados nos processos de trabalho. Seja por falta de coordenação individual ou por uma série de ações das quais os(as) profissionais de um determinado serviço devem cotidianamente dar conta, eles(as) têm se sentido impedidos(as) de, por exemplo, manter processos de articulação e diálogo, que poderiam servir como instâncias estratégicas para mais bem atender a suas demandas e seus objetivos.

Acreditamos que espaços de diálogo, como os instaurados pela pesquisa, podem servir como espaços importantes para que os(as) profissionais (re)conheçam suas práticas, discutam e ampliem suas possibilidades de elaborar ações mais inclusivas, produzindo conhecimentos a partir do exercício de estranhar suas práticas; esse é um movimento que pode, ainda, contribuir para fortalecer a responsabilidade profissional em outra direção que não essa que estamos aqui identificando como responsabilização individual. Trata-se de um movimento de olhar de fora nossas ações, como se não as conhecêssemos, buscando tensionar as teorias e as práticas que nos constituem tão profundamente. Desse modo, podem se tornar visíveis os efeitos concretos de suas operações e significados, sem desconsiderar seus processos mais amplos de produção.

O conjunto de elementos explorados neste artigo nos leva a perceber a importância de examinarmos as políticas de inclusão social buscando tanto (re) conhecer o contexto social de criação, objetivos e metas, quem deve se tornar o público-alvo (ou quem é tomado como foco), condicionalidades, ampliação de acesso aos direitos sociais e cidadania, assim como colocar sob suspeita seus imperativos e suas promessas, para problematizar alguns de seus efeitos. Tendo apresentado o tema e realizado o exame de alguns desses efeitos a partir dos resultados de uma pesquisa sobre políticas de inclusão social, passamos agora às considerações finais.

\section{Sem promessas e sem imperativos, o que nos resta?}

Procuramos argumentar, com as análises apresentadas neste artigo, que imperativos e promessas em torno da inclusão social podem ser questionados. O questionamento que fizemos, entretanto, procurou não se apoiar em posições morais do que seria supostamente mais apropriado - melhor, mais avançado, privilegiado. Nossa intenção não foi a de confirmar se as políticas públicas 
contribuem ou não para a inclusão social, ou ainda se elas atingem as metas a que visam produzir. Ao operar a partir dessas desconfianças, não nos inscrevemos em uma posição de quem não deseja e não investe em uma sociedade inclusiva, tampouco estamos negando ou desconhecendo os impactos que as políticas e programas de inclusão social produzem diminuindo a mortalidade infantil, ampliando os níveis de permanência na escola e a escolaridade de crianças e jovens ou, ainda, os níveis de acesso a alguns equipamentos públicos e de participação social.

Apostando em outro viés de análise, tais imperativos e promessas foram, aqui, problematizados por meio da análise de seus efeitos, os quais contribuem, neste caso, para instituir processos de responsabilização de determinados tipos de sujeitos: responsabilização tanto pela busca de soluções para os problemas que vivenciam no cotidiano dos serviços quanto pelo sucesso ou fracasso das ações previstas nessas políticas de inclusão social. Em convergência com essa abordagem, procuramos romper com análises normativas que enfatizam parâmetros como certo e errado, adequado e inadequado, para dar visibilidade a diferentes e divergentes entendimentos que cada técnica tem sobre as ações que executa, sobre as diretrizes governamentais em torno da inclusão social e sobre os próprios significados deste termo nos dias atuais. Empreendemos uma análise com o objetivo de pensar na produtividade de se operar com alguns entendimentos do que vem a ser inclusão social, e nos efeitos concretos que essa operação produz no cotidiano dos serviços, nos(as) profissionais e usuários(as). Focalizando modos pelos quais profissionais falaram sobre suas ações e sobre serviços ofertados por secretarias municipais de educação, saúde e desenvolvimento social em um município do Rio Grande do Sul, sinalizamos alguns atravessamentos desses imperativos e promessas de inclusão social, os quais estabelecem outras/novas ordens sociais, atualizam formas de in/exclusão e instituem hierarquias e posições para os sujeitos com elas envolvidos. Pudemos ressaltar, ainda, que esses imperativos e promessas em torno da inclusão social instituem modos de organização do trabalho, bem como modos de fazer profissionais que posicionam e responsabilizam técnicas e profissionais como agentes fundamentais para a concretização da inclusão social em um dado tempo e lugar. Assim, torna-se possível retomar aqui um pressuposto já anunciado neste artigo, o qual sugere problematizar as políticas (em sentido lato) como tecnologias de poder, por entender que elas funcionam tanto como instrumentos de organização da sociedade, quanto incidem sobre os modos pelos quais os 
indivíduos constroem a si mesmos como sujeitos, modificando suas condições de vida e criando formas de categorização desses sujeitos - profissionais da inclusão social, por exemplo.

Acreditamos que a problematização desses imperativos e promessas de inclusão social e seus efeitos pode provocar reflexões sobre os modos com os quais temos trabalhado pela redução da pobreza e da desigualdade social. Reflexões sobre quais são os efeitos produzidos por ações que visam à inclusão social e como, enquanto profissionais envolvidos com as políticas sociais, podemos lidar com tais efeitos sem que isso nos provoque paralisia intelectual e, tampouco, culpabilizações e responsabilizações que levam ao desânimo e ao adoecimento, na medida em que visibilizam usualmente o que deveria ter sido feito e não se fez, ao invés do que foi/é possível fazer.

No nosso caso, com a interrogação acerca dos processos de in/exclusão que constituem as (e são constituídos pelas) políticas e instituem modos de ser profissional da saúde, da educação, da assistência social, buscamos criar condições para a revisão das próprias políticas, das ações dos(as) profissionais executores(as) das políticas bem como sobre nossas formas de analisá-las. Nessa revisão, apostamos na possibilidade de criação de práticas no interior das políticas de inclusão social que não visam propriamente a romper o seu curso, que possam potencializar movimentos de contraconduta ${ }^{21}$ e permitam traçar outros caminhos para a condução dos sujeitos em situação de in/exclusão social, política e educacional. Assim, torna-se possível forjar novas formas de pensar e de agir para continuar aprofundando o debate e, possivelmente, para (re)formular políticas e ações de promoção da inclusão social adequadas à realidade contemporânea.

21 No curso Segurança, território, população (1977-1978), Foucault examina a problemática do governo, designado por ele de "condução de condutas". Trata-se tanto da arte de conduzir alguém como também de seu contrário, qual seja, conduzir-se de outro modo, mediante uma contraconduta. Segundo Foucault (2008b), o movimento de contraconduta teria como objetivo outra conduta, isto é, "[...] querer ser conduzido de outro modo, por outros condutores e por outros pastores, para outros objetivos e para outras formas de salvação, por meio de outros procedimentos e de outros métodos" (p. 257). Pode-se afirmar, então, que a condução da conduta está intrinsecamente relacionada com a contraconduta. Nas palavras de Foucault (2008b, p. 258), existe "uma correlação imediata e fundadora entre a conduta e a contraconduta". 


\section{Referências}

ALBUQUERQUE, R. C. Uma avaliação do atual processo de inclusão social no Brasil. In: FÓRUM NACIONAL, 22., 2009. Disponível em: $<$ http:// forumnacional.org.br>. Acesso em: 22 maio 2013.

ALVARENGA, L. F. C. Flores de plástico não morrem? Educação, Saúde e Envelhecimento na perspectiva de Gênero. Dissertação (Mestrado em Educação)-Universidade Federal do Rio Grande do Sul, 2006.

AMARAL JR., A.; BURITY, J. A. Apresentação. In: AMARAL JR., A.; BURITY, J. A. (Org.). Inclusão social, identidade e diferença: perspectivas pós-estruturalistas de análise social. São Paulo: Annablume, 2006. p. 9-18.

ANDRADE, S. A(s) juventude(s) que não vemos: narrativas de jovens sobre exclusão escolar, gênero, raça/cor e classe social. Tese (Doutorado em Educação)-Universidade Federal do Rio Grande do Sul, Porto Alegre, 2008.

ARRUDA, R. "Programa não é suficiente para mudar desigualdade". $O$ Estado de São Paulo. São Paulo, 13 jan. 2013. Entrevista com Alexandre de Freitas Barbosa. Disponível em: <http://digital.estadao.com.br/download/ pdf/2013/01/13/a8.pdf $>$. Acesso em 20 jan. 2013.

BAUMAN, Z. Vidas desperdiçadas. Rio de Janeiro: Jorge Zahar, 2005.

. A sociedade individualizada: vidas contadas e histórias vividas. Rio de Janeiro: Jorge Zahar, 2008.

BRASIL. Ministério da Saúde. Secretaria de Atenção à Saúde. Manual Prático de implantação da rede cegonha. 2011. Disponível em: <http://migre.me/ d6AB5>. Acesso em: 8 dez. 2012.

. Presidência da República. Secretaria de Comunicação Social. Bolsa Família completa nove anos atendendo 13,7 milhões de famílias pobres ou em extrema pobreza. Disponível em: <http://migre.me/d6AjA> . Acesso em: 30 nov. 2012.

CANGUILHEM, G. O normal e o patológico. Rio de Janeiro: Forense Universitária, 2002. 
CASTEL, R. A discriminação negativa: cidadãos ou autóctones? Petrópolis: Vozes, 2008.

DAL'IGNA, M. C. Família S/A: um estudo sobre a parceria família-escola. Tese (Doutorado em Educação)-Universidade Federal do Rio Grande do Sul, Porto Alegre, 2011.

DAMICO, J. G. S. Juventudes governadas: dispositivos de segurança e participação no Guajuviras (Canoas-RS) e em Grigny Centre (França). Tese (Doutorado em Educação)-Programa de Pós-Graduação em Educação, Universidade Federal do Rio Grande do Sul, Porto Alegre/RS, 2011.

EWALD, F. Foucault, a norma e o Direito. Lisboa: Veja, 2000.

FERNANDES, L. P. Nas trilhas da família... Como e o que um serviço de educação social de rua ensina sobre relações familiares. Dissertação (Mestrado em Educação)-Universidade Federal do Rio Grande do Sul, Porto Alegre, 2008.

FOUCAULT, M. O sujeito e o poder. In: DREYFUS, H. L.; RABINOW, P. Michel Foucault - uma trajetória filosófica: para além do estruturalismo e da hermenêutica. Rio de Janeiro: Forense-Universitária, 1995. p. 231-249.

. Vigiar e punir: nascimento da prisão. Petrópolis: Vozes, 2000.

. Nascimento da biopolítica. São Paulo: Martins Fontes, 2008a. (Coleção Tópicos).

. Segurança, território e população. São Paulo: Martins Fontes, 2008b. (Coleção Tópicos).

GADELHA, S. Biopolítica, governamentalidade e educação: introdução e conexões, a partir de Michel Foucault. Belo Horizonte: Autêntica, 2009.

GILES, J.; MIDDLETON, T. Studying culture: a practical introduction. Oxford (UK): Blackwell Publishers, 1999.

HALL, S. Representation: cultural representatios and signifying practices. London: Sage; Open University, 1997. 
KLEIN, C. “...um cartão [que] mudou nossa vida”? Maternidades veiculadas e instituídas pelo Programa Nacional Bolsa-Escola. Dissertação (Mestrado em Educação)-Universidade Federal do Rio Grande do Sul, Porto Alegre, 2003.

- Biopolíticas de inclusão social e produção de maternidades e paternidades para uma "infância melhor". Tese (Doutorado em Educação)Programa de Pós-Graduação em Educação, Universidade Federal do Rio Grande do Sul (UFRGS), Porto Alegre/RS, 2010.

LASTA, L. L. Entre leis e decretos sobre inclusão: a produção de sujeitos. Dissertação (Mestrado em Educação)-Programa de Pós-Graduação em Educação, Universidade de Santa Cruz do Sul (Unisc), Santa Cruz/RS, 2009.

LOPES, M. C.; DAL'IGNA, M. C. (Org.). In/Exclusão nas tramas da escola. Canoas: ULBRA, 2007.

. Políticas de inclusão e governamentalidade. Educação \& Realidade, Porto Alegre, v. 34, n. 2, p. 153-169, maio/ago. 2009.

LOPES, M.C. et al. Inclusão e Biopolítica. Cadernos IHU Idéias, São Leopoldo, n. 144, p. 3-30, 2010.

MEYER, D. E. E. Educar e assistir corpos grávidos para gerar e criar seres humanos saudáveis: educação, saúde e constituição de sujeitos "de direitos" e "de riscos". Porto Alegre: Faculdade de Educação, Universidade Federal do Rio Grande do Sul, 2005. (Relatório de Pesquisa).

A politização contemporânea da maternidade: construindo um argumento. Gênero, Niterói, v. 6, n. 1, p. 81-104, 2006.

. Vulnerabilidade, programas de inclusão social e práticas educativas: uma abordagem na perspectiva dos estudos de gênero e culturais. Porto Alegre: Faculdade de Educação, Universidade Federal do Rio Grande do Sul, 2008. (Projeto de Pesquisa).

MEYER, D. E. E.; KLEIN, C.; FERNANDES, L. Noções de família em políticas de "inclusão social" no Brasil contemporâneo. Estudos Feministas, Florianópolis, v. 20, n. 2, maio/ago. 2012. 
MILITÃO, M. J.; PINTO, C. Governamentalidade, cultura política e a reflexividade dos riscos sociais: o caso da política portuguesa de inclusão social. In: CONGRESSO PORTUGUÊS DE SOCIOLOGIA, 6., 2008. Disponível em: $<$ http://www.aps.pt/vicongresso/pdfs/202.pdf $>$. Acesso em: 22 jan. 2014.

RECH, T. L. A inclusão escolar no governo FHC: movimentos que a tornaram uma "verdade" que permanece. Dissertação (Mestrado em Educação)-Programa de Pós-Graduação em Educação, Universidade do Vale do Rio dos Sinos, São Leopoldo, 2010.

SASSAKI, R. K. Panorama geral da inclusão social. In: SEMINÁRIO DE POLÍTICAS PÚBLICAS DO MUNICÍPIO DE LIMEIRA SOBRE PESSOAS COM DEFICIÊNCIA, 1., 2003. Disponível em: <http://www.ceset.unicamp. br>. Acesso em: 22 jan. 2014.

SCHUCH, P.; FONSECA, C. Introdução. In: SCHUCH, P.; FONSECA, C. (Org.). Políticas de proteção à infância: um olhar antropológico. Porto Alegre: Editora da UFRGS, 2009. p. 9-17.

SHORE, C.; WRIGHT, S. Anthropology of policy: critical perspectives on governance and power. London: Routledge, 1997.

TURCHIELLO, P. A hora e a vez da familia em uma sociedade inclusiva: problematizando discursos oficiais. Dissertação (Mestrado em Educação)Programa de Pós-Graduação em Educação, Universidade Federal de Santa Maria, Santa Maria, 2009.

VEIGA-NETO, A. Neoliberalismo, império e políticas de inclusão: problematizações iniciais. In: RECHICO, C. F.; FORTES, V. G. (Org.). A educação e a inclusão na contemporaneidade. Boa Vista: UFRR, 2008. p. 11-28.

. Incluir para excluir. In: LARROSA, J.; SKLIAR, C. (Org.). Habitantes de Babel: políticas e poéticas da diferença. Belo Horizonte: Autêntica, 2011. p. 105-118.

VEIGA-NETO, A; LOPES, M. C. Inclusão e governamentalidade. Educação \& Sociedade, Campinas, v. 28, n. 100, p. 947-963, out. 2007. 
VEIGA-NETO, A; LOPES, M. C. Gubernamentalidad, biopolítica e inclusión. In: SALCEDO, R. A. C.; DÍAZ, D. L. M. (Org.). Gubernamentalidad y Educación: discusiones contemporâneas. Bogotá/Colombia: Instituto para la Investigación Educativa y el Desarrollo Pedagógico (IDEP), 2011. p. 105-126.

\section{Public Policies: Imperatives and Promises of Social Inclusion \\ Abstract}

This article proposes to analyze part of the results of a research that examines public policies for social inclusion, focusing on the implementation process, the services offered by the municipal departments of education, health and social development of a city in Rio Grande do Sul and the individuals that perform programmatic actions resulting from these policies. Based on the fields of Gender Studies, Cultural Studies and Sociology of Health, on the aspects that approach to Michel Foucault's post-structuralism, discusses imperatives and promises

of social inclusion that contribute to establish responsibilization procedures of subjects both for the success or failure of the actions specified in these policies for social inclusion and the search for solutions to the problems they experience in everyday life throughout those services. It is also discussed that this discursivity institutes modes of work organization, as well as professional ways of doing. Keywords: Public Policies. Social Inclusion. Public Services. Post-structuralism.

\section{Políticas públicas: imperativos y promesas de inclusión social \\ Resumen}

Este artículo tiene por objeto analizar parte de los resultados de una investigación que analiza las políticas públicas de inclusión social, enfocando su proceso de implementación, los servicios de las secretarías municipales de educación, salud y desarrollo social de una ciudad de Río Grande del Sur y los sujetos que ejecutan las acciones programáticas derivadas de estas políticas. Basado en los Estudios de Género, en los Estudios Culturales y en la Sociología de la Salud, en las líneas teóricas que más se aproximan al postestructuralismo de Michel Foucault, problematiza imperativos y promesas de inclusión social que contribuyen para 
instituir procesos de respondibilidad de los sujetos tanto por el éxito o por el fracaso de las acciones previstas en esas políticas de inclusión social como por la búsqueda de soluciones para los problemas que viven en la experiencia cotidiana de los servicios. Se argumenta, además, que esta discursividad establece modos de organización laboral, así como modos de hacer profesionales.

Palabras clave: Políticas públicas. Inclusión social. Servicios públicos. Postestructuralismo. 